ISSN: 2288-7709 (C) 2020 ICMA. http://www.icma.or.kr doi: http://dx.doi.org/10.20482/jemm.2020.8.1.12

\title{
A Causal Analysis of Conglomerate Bankruptcies
}

\author{
Sang-Wuk KU ${ }^{1}$, Yun-Oh WHANG ${ }^{2}$ \\ 1, First Author Associate Professor, Department of Convergence Studies, Pai Chai University, Korea. Tel: +82-42-520- \\ 5903, Email: gabsan@pcu.ac.kr \\ 2, Corresponding Author Clinical Assistant Professor, College of Business Administration, University of Pittsburgh, U.S.A. \\ Tel: +1-412-648-1710, Email: ywhang@katz.pitt.edu
}

Received: November 15, 2019. Revised: February 2, 2020. Accepted: March 4, 2020.

\begin{abstract}
Purpose - Strategic causes for the failure include unrealistic growth, overexpansion, unfamiliar new markets, volume obsession, unrealistic promises and poor project selection. Organizational causes are insufficient capital and profits, lack of business knowledge, poor financial management, poor sales skills, inadequate marketing, poor leadership, poor leadership transfer, project losses, poor field performance and owner bankruptcy. Uncontrollable causes include industry and economic weakness and banking and surety changes. While helpful, the list provides insufficient clarity regarding the causal roots of failure.

Research design, data and methodology - The research framework to organize the information involved with many of the recent and large failures in the industry.

Results - This research then identified five dominant root causes - excessive egoism, poor strategic leadership, too much change, loss of discipline and inadequate capitalization.

Conclusion - Finally, additional input from external forces may accelerate the firm's pace to failure. It is important on the development of diagnostic tools that are based on this model and that will provide new ways to assess a conglomerate's level of risk for incurring a financial crisis.
\end{abstract}

Keywords: Conglomerate Bankruptcy, Excessive Egoism, Poor Strategic Leadership, Pushing the Speed Limits of Change, Loss of Discipline, Inadequate Capital

\section{JEL Classification Code: L1}

\section{Introduction}

The description of "too big to fail" has been used to describe large banks whose failure would cause a chain reaction among other banks and financial institutions in their network.

The theory is that it is in the best interests of the national economy to provide liquidity to assure that these banks don't fail. Some analysts have said that several big conglomerates may fall into the too-big-to-fail category. However, most experts agree that government bailouts (Aziz et al., 2016; Gray et al., 2015) should be rarely, if ever, applied in a free market system (Röpke, 2014). 
So can a corporation be too big to fail? Recent history has shown that firms are not too big to fail, even though they may have annual revenues ranging from hundreds of millions to several billions of dollars. During the past few decades, there have been dozens of large conglomerates globally that, after many years of growth and apparent prosperity, experienced notable financial disasters (Klomp, 2014), resulting in bankruptcy or a reincarnation of the business in a much different form.

There are bonding safeguards to protect project owners and others when a conglomerate fail, however, there are no such safeguards for the conglomerates themselves. Such an event affects not only the employees and shareholders of the firm but also the industry as a whole.

\section{What causes large and historically successful conglomerates to self-destruct?}

The industry has regularly witnessed smart leaders making what appear to be the same fatal mistakes others have made before them. While lists of the major reasons for conglomerate failure have been circulated in the past, many industry leaders said something was missing in those lists. It is expected that this effort will improve the endurance and longevity of the high-quality conglomerates serving the needs of our society.

Many of the characteristics that are unique to the industry are also key contributors to conglomerates' financial difficulties. High leverage for conglomerates does not usually mean a lot of debt, though that can be the case too. More typically for the industry, this refers to the amount of revenue pushed through the pipeline compared to the underlying equity base or level of working capital. Conglomerates, especially in the building market, can do a large amount of business with a little bit of equity. Leveraging working capital (Sainani et al., 2017; Rehman et al., 2017; Khoo et al., 2017; Tao et al., 2017; Kucséber, 2016) or leveraging equity (Zhao, 2017; Salvi et al., 2018) is what we mean by "leverage" in the industry. Workforce issues represent an industrywide problem that is becoming more and more critical to the success of an industry firm. The industry is a people business, and without the right people in the right places, conglomerates are bound to get into trouble. Where are these people going to come from, and where will a firm find technically qualified people to do the work in the pipeline now and in the future? The cyclical nature of the industry signifies that activity rises and falls faster than the overall economy. Such fluctuations (Li and Wang, 2016; Adnan and Hossain, 2016; Hongjiang, 2015; Zou et al., 2015) lead to being overcommitted or scrambling for work to keep people busy. The hard bid process is unique to the business. The way work is procured in a large part of the industry is different from the way most businesses work. The owner wants a building and wants to know exactly how much it is going to cost before the project is built. Increasing complexity of projects, fluctuating material costs and labor concerns all conspire to make this a dangerous practice for conglomerates. While the predominance of this method is changing with new delivery methods, it is easy to see how conglomerates still get into trouble here. Project timing is dictated by owners' schedules, leaving conglomerates with little control over project start dates. Sometimes project opportunities become available at the same time, leading to over-commitment of company human and financial resources for the conglomerate. Backlogs can fluctuate widely. A related issue is the long project durations, which can result in project impacts due to material, labor, weather, and related issues. Derived demand is an interesting concept when applied to a conglomerate. Most businesses think they have the ability to affect the demand for their service or product. If a conglomerate wants more business, then it conducts more marketing to create the demand for its product or service. On the other hand, conglomerates are always responding to opportunities, unless they are able to create a new project and provide the financing as in some design-build (Pena-Mora et al., 2001; Ling et al., 2004; Chan et al., 2002) or public-private-partnership (Osborne, 2002; Akintoye et al., 2008) type projects. So conglomerates are at the mercy of the work that comes their way. This easily leads to the project timing issues noted previously. The industry is hypercompetitive (Volberda, 1996) with tight and low-margin business. Why is the industry so competitive? Most businesses are easy to get into; low barriers to entry (Bain, 1956) and price-driven competition (Weinstein, 1984) lead to a very competitive industry. In addition, when every project is unique, conglomerates do not get to practice. The learning curve (Yelle, 1979; Spence, 1981) can be expensive, and not all learning is portable to the next project.

In this research, culture and systems of the organization played an important role in a firm's downfall. Under this general category are several issues and management areas. Lack of financial discipline generally means the business is not being managed like a real business. Some conglomerates are not good business-people. They are good builders, but they don't give the financial side of the business the attention it deserves. For example, at some firms the financial people are not involved in decision-making; instead, they are relegated to bookkeeper status with the 
thinking that the only real work of a business is production. Succession planning $(\mathrm{Ku}, 2014$; Rothwell, 2010) is often missing or mismanaged in the industry. This makes it a particularly precarious time when, for example, the longtime leader or founder is ready to leave the business, or when unforeseen circumstances cause sudden leadership changes. Similar concerns occur in transitions that involve subsequent generations as well. Ensuring that a strong leader is replaced with another strong leader when the time is right assuring the continuity of the business and future growth. This does not happen often enough in the industry. A poor project owner selection process ties back to the project timing and hard-bid process macro causes for conglomerate failure outlined above. Many conglomerates do not have a well-defined process for making go or no-go decisions when deciding whether to take on a project. Innovation is required to win the work and to build it profitably. Many companies do strategic planning but don't have very good strategies. They tend to be so caught up in the process that they forget that their task is really to determine what kind of company they are and where the company should be headed. Instead, their "strategic" planning becomes an operational fix-it list. Companies that do not maintain adequate capital reserves are running on the razor's edge. One misstep can cause them to fall into the cycle of failure. This management aspect is a critical area that affects the long-term sustainability (Ostrom, 2009) of a conglomerate. It is often sabotaged by other corporate and personal demands, leading to the company's demise. Since most industries are people businesses, all aspects of human resource management are important. Finding and retaining the talent needed to do the job is critically important for firms. Corporate culture (Kotter, 2008) issues have gained recognition in recent years as being more important than historically thought. This area is especially notable when clashes in corporate culture are cited as leading to a company's end. Ethical and moral issues (Goodpaster, 1991) are some of the more serious areas of corporate culture failures, but a company's culture also affects decisions about a company's strategy and hiring needs. The strength of a company's culture dictates not only its ability to hold firm on the practices needed to maintain a financially disciplined organization but also its capacity to change and meet the never-ending evolution of the market and the competition. This research on failed organizations indicates that cultural issues often contributed to company failures.

One of the most surprising and perhaps most interesting results of this research is a greater understanding of the role played by the mind of the conglomerate. Some of the characteristics that contributed to the success of an individual leader also contributed to the company's collapse. Most conglomerates are by nature driven to grow their business. They want to build the biggest job or perform the most volume. If the firm is a public firm, the market expects it to grow. Part of that expectation is the belief that profits will grow along with revenues. This result is often not the case. Conglomerates are also by nature action-oriented (Sturkenboom et al., 2001), rapid decision-makers who sometimes act too quickly when a more deliberate approach is needed. Most leaders in the industry came from the operations side of the business. Most were former project managers or superintendents. While this is a critical background for an executive, the CEO's job is to run the business, not the projects. Some leaders never make this transition. Getting the next project and building the backlog seem to overshadow all other considerations - frequently leading to taking the wrong job for the wrong reasons. Manufacturing with highly intensive capital is a high-risk business, so it is not surprising that those who venture into this business are numb to its inherent risks. Or, after decades of facing these risks and succeeding, the conglomerate often develops calluses to these risks. Many people outside the industry consider the risk conglomerates assume compared to the low margins gained. Yet, the people running companies don't see it that way. Instead, they sign personally for bank loans and bond guarantees thinking it is no big deal. They believe they can control the risks. They have strong egos and a can-do attitude. This supreme confidence can be a great characteristic for a conglomerate, but it can similarly lead to the downfall of the business. Being afraid of layoffs is linked to the concern conglomerates have for finding and keeping the right people as well as the drive to grow the business and the cyclicality of the industry. Most firms that have built up a good workforce in good times naturally want to keep people busy until the next big job comes along. But this can lead to inflated overhead, fattened job costs and poor project selection.

When the conglomerate's mindset, company culture, general economic conditions and the nature of the industry combine to create poor company performance, the result is oftentimes the loss of financial capacity. Before a firm loses financial capacity, however, symptoms of this impending loss can be detected through measures of company performance. In fact, most models that predict the potential of a firm's failure employ some of these financial measures. Unfortunately, by the time these lagging metrics indicate a problem, it is usually too late. The conglomerate will typically have already lost its financial capacity and will be scrambling to pay its bills and employees.

The end stages of the model show the interactivity of causes that can lead to a loss of financial capacity, which in turn can ultimately lead to bankruptcy doom loop. Once a firm has lost its financial capacity, failure is almost 
inevitable. Loss of financial capacity is the ultimate trigger of the downward spiral that includes a decline in surety bonding, the calling of bank loans and the inability to make payroll and pay suppliers.

Strategic causes for the failure include unrealistic growth, overexpansion, unfamiliar new markets, volume obsession, unrealistic promises and poor project selection. Organizational causes are insufficient capital and profits, lack of business knowledge, poor financial management, poor sales skills, inadequate marketing, poor leadership, poor leadership transfer, project losses, poor field performance and owner bankruptcy. Uncontrollable causes include industry and economic weakness and banking and surety changes. While helpful, the list provides insufficient clarity regarding the causal roots of failure.

\section{A model of the paths to financial crisis}

Overall, this research isolated about potential factors that can lead to conglomerate failure. In digging behind these factors, we realized that no single factor would usually signal the impending doom of a firm. More than one issue is most always involved. Failing companies usually exhibited a combination of factors that interacted, causing company performance to spiral toward inevitable bankruptcy. A business with highly intensive capital is a dynamic and risky business, and, as such, it appears that the causes of conglomerate failure are similarly dynamic and involve a number of difficult-to-manage risk factors.

To illustrate the causes of conglomerate failure and how they relate to one another categorizes the causes of conglomerate failure into four major groups, ranging from macro to micro conditions. General economic conditions and nature of the industry represent the macro conditions in the model. The micro conditions are represented by culture and systems of the organization and mind of the conglomerate. Company performance results from the combination of these four categories. Ultimately, poor company performance leads to loss of financial capacity, which is the final step toward a downward spiral - the "Bankruptcy Doom Loop." Each component of the model is explained further in the following sections.

General economic conditions affect conglomerates through many paths including bonding issues, demographics, government policy, tax law, consumer confidence and even material shortages. For example, conglomerates may blame their financial disaster on a lack of available work due to a suppression of business plans that is caused by an increase in interest rates. However, the validity of blaming external economic conditions may be the primary cause of a firm's financial collapse. The fact that not all conglomerates fail during difficult economic times indicates that there are other causes that are more relevant.

The research framework to organize the information involved with many of the recent and large failures in the industry. This research then identified five dominant root causes - excessive egoism (Dohrenwend, 1959), poor strategic leadership (Finkelstein et al., 1996; Vera et al., 2004; Ireland and Hitt, 1999; Finkelstein et al., 2009), too much change, loss of discipline and inadequate capitalization.

First of all, in this business, pride and ignorance go together, and experience and humility go together. The concept of excessive egoism embodies a constellation of attitudes and beliefs (Dohrenwend, 1959) that in many ways point to a leader's ability to succeed. However, those same attitudes can often be identified as the root causes leading the company to failure. The concept of a two-edged sword could not be more applicable here. Pride, arrogance, overoptimism, and blindness to realities are often characteristics of a leader who fails to develop a team or seek candid feedback. Such leaders may also develop a sense of invincibility. There are many ways in which an excessive ego can distort reality, leading to misperception concerning the market, the conglomerate's capabilities and the leader's personal needs, any of which can put the firm at much greater risk of failure. Financial crisis displayed high-ego attitudes more frequently than firms with lower risk.

Most of the statements are familiar to those who have worked in the industry for any length of time, and it is not hard to see how such attitudes can get a conglomerate into trouble. While this approach sometimes works as a conglomerate scrambles to put people on the job, it also frequently leads to lower margins and late projects. When this approach does work, it builds the leader's ego to the point that a sense of invincibility is reinforced, which can lead to taking greater risks until disaster strikes. When too many of these ego-centric attributes come together with other factors, the risk for failure in these companies appears to increase. If the perils of excessive ego appear to be 
obvious, why do companies or leaders let these attitudes get them into trouble? Often, there is a short distance between the self-confidence needed to assume the risks typical of an entrepreneur and the overconfidence that precipitates the fall of the unsuccessful conglomerate.

Second, poor strategic leadership was cited as a leading factor in the business failure (Finkelstein et al., 2009). For instance, one executive of a public company that ran into serious financial difficulty said: Everything comes back to leadership; all the decisions were made by me and a few other people in upper management. Once made poor leadership management decisions, there were certain operational failures where lower-level people made erroneous decisions, causing systems and business processes not to work as intended (Finkelstein et al., 1996; Vera et al., 2004). The problems all stemmed from bad choices made at the top.

A leader's excessive ego often leads directly to "poor strategic leadership," which is typically the root of a conglomerate's financial difficulties (Ireland and Hitt, 1999). Another leadership weakness leading to corporate collapse is not having any or enough "skin in the game." This results in a renter's attitude rather than that of an owner. The lack of a personal presence, i.e., absentee leadership, results in insufficient awareness and control of the organization (Finkelstein et al., 1996; 2009). Strategic mistakes resulted. Just as overconfidence can produce wrong decisions bringing down companies, indecision can lead to problems not getting resolved, which can equally topple companies. Not grooming new leaders and successors, showing little understanding of the finances and core aspects of the business, not having an ability to make difficult decisions, and other factors from the responses indicate poor strategic leadership (Finkelstein et al., 1996; 2009). Sometimes the wrong person gets the top job.

In fact, excessive change appears to be the root cause behind many of the more surface-level causes that are often identified (Finkelstein et al., 1996). Examples of these surface-level causes include a sudden increase in the volume of work, entry into new geographic markets, working with new owners and choosing to offer new services. In addition, hiring new senior leaders, changing ownership, hiring new project managers and even installing a new accounting system can all be changes that set events in motion toward the failure of the organization (Finkelstein et al., 1996; Vera et al., 2004). With each increment of change, there is an exponential increase in the risk of losing the systems of procedure and control that are so fundamentally critical to bringing projects in on time and on budget, and maintaining satisfied owners and employees. Changing too much too fast leads to problems. The analysis supports the concept that a constant, yet moderate, pace of change is the best route for a conglomerate.

Third, regarding pushing the speed limits of change, this part considered a graph along the lines of the supplydemand graphs used in economic theory. The $\mathrm{X}$-axis along the bottom of the diagram represents the total amount of change within the organization occurring at one time. The vertical Y-axis represents amounts of resources, which can be machines and internal systems such as computers, production equipment, and accounting systems, but primarily is used to represent human resources regarding the mental capacity for change as well as simply the number of employees in the firm. The upwardly sloping line represents the resources required to accommodate change, and the downwardly sloping line represents the resources available or remaining to accommodate the changes being made in the company. As the amount of change increases, the amount of resources used to accommodate the change increases and the amount of resources available to accommodate additional change decreases. The rate of change speed limit is the point at which the upwardly sloping line intersects the downwardly sloping line. It is at this point that the company is operating at its speed limit, or maximum level of change, using all of its resources to accommodate the changes being made. If the company exceeds its speed limit, the ability for it to maintain its discipline and quality of work is severely compromised, and there is an increasing risk of instability leading to failure.

For example, the PMI (post-merger integration) of Hyundai Electronics and LG Semiconductor in 1999 shows an implication on the speed limits of change. In the above diagram as discussed, the X-axis represents the total number of redundant employees of two merged companies because of PMI. The Y-axis represents the total number of new employees within a new company after PMI. The upwardly sloping line represents the degree of new training programs to acquire newly innovative capabilities and the number of newly recruiting employees according to the established corporate strategy after PMI, and the downwardly sloping line represents the redundant machines and internal systems such as production equipment, production sites, and so on.

Fourth, when it comes to loss of discipline, whether it occurs because of too much change or is a gradual decay, the loss of discipline is one of the most caustic root causes of conglomerate failure. The importance of maintaining discipline in the management and operations of a conglomerate is not different from the importance of discipline in 
the processes employed in producing products or services. If the measurements are off or attention to detail is neglected, cost overruns and on-the-job accidents become the focus of attention. The analogies for management include, but are not limited to, staying true to appropriate project selection and pricing policies, taking efforts to maintain an entrepreneurial spirit, avoiding bloated overhead and complex organizational structures, and not succumbing to the impulse of needing to feed the beast or take the seldom-actualized break-even project just to keep people busy. Executives and managers assert that how well a company is believed to be keeping its eye on the ball is directly related to its risk of financial crisis. Keeping the company's eye on the ball is not changing from proven practices regarding solid hiring, training, employee retention, accepted project risk level or proper forecasting or cost controls. Executives and managers in companies that had experienced a financial crisis more frequently reported their company took on strategies that did not fit core competencies and seldom had a culture that supported learning from mistakes. In contrast, executives and managers from companies believed to have a low likelihood for a financial crisis reported their company's behavior as being more disciplined. Companies that lack a good growth strategy or are inattentive in deploying their strategy can end up with more infrastructure than the company can support. The result is a lack of strategic focus (McDowell et. al., 2016; Seal, 2001), inefficiency on resources (Adler, 1993; Berkovitch, 1998), and the urge to chase projects that don't fit the business. Lack of discipline is often seen in the lack of a way that the company does things. There is no standardization of processes or systems. There are many ways that a loss of discipline can get a company into trouble, and it is a strong sign that a company may be heading toward failure.

The last major root cause for conglomerate failure is having inadequate capital (Hackney \& Benson, 1981; Jagtiani et al., 2000). This refers to companies that maintain a level of capital (Trueman, 1986) that is inadequate for ensuring a sufficient buffer for sudden and unexpected needs. The economics of an industry are rather unique and many leaders fail to grasp the severity of risk by maintaining an inadequate amount of capital. The list of issues related to an inadequate amount of capital is long. A financial policy that is too liberal and that consistently targets a level of contingency and reserves that is inadequate. Being forced to litigate disputes since the capital base is inadequate to allow compromise. Large projects for the product development with long-duration cause significant equity, cash and working capital to be tied up in uncompleted work or claims. Because of pressure to show profits prematurely, equity reflected in percent of sales estimates to the specific goals does not reflect appropriate profits. Regarding ownership-related capital depletion (Maupin, 1987), stockholder buyouts lower the capital base of a company. Diversification into illiquid assets (Longstaff, 2009; Battistonet al., 2012) does not provide cash available to solve problems that may arise. As cash runs short, too much time is spent managing cash and taking focus away from a business. Over-borrowed situation is another problem that too much debt means too little real equity. Overpayment for acquisitions (Olante, 2013; Moeller et al., 2004; Black, 1988) also brings about an inadequate amount of capital. Leadership sometimes envisions unspoken assumption that the firm will incur no bad luck. Leaderships tend to rely on phantom investment (Damgaard et al., 2019), which is for the equity reflected on a balance sheet that is made up largely of estimated profits on uncompleted work. Prudent management dictates that the firm's equity and working capital levels should be maintained at a level to survive unforeseen problems.

\section{Conclusion}

Many people from failed companies point to issues outside the control of their company as the causes of its demise. Yet, in any market at any time, you can find examples of companies that succeeded despite the same external force being present when another company suffered a catastrophic financial event. In fact, in this study, many seasoned industry executives emphatically rejected the notion that luck or other extraneous forces are responsible for a company's decline. This study indicates that these externalities are not root causes but actually accelerants that quicken the pace of demise for those companies that already suffer from one or more of the root causes noted. It is a rather thin edge on which successful conglomerates live. A significant misstep can end the life of a conglomerate. The depth and complexity of the troubles that take large conglomerates down is evident; more liquidations than reorganizations. This illustrates the interplay of the critical root causes that lead to poor financial performance, which aggravates the issue of maintaining adequate capital and then creates capital erosion. Finally, additional input from external forces may accelerate the firm's pace to failure. It is important on the development of diagnostic tools that are based on this model and that will provide new ways to assess a conglomerate's level of risk for incurring a financial crisis. Whereas the majority of this work has always been to help improve corporate strength and value, it is now clear that the activities required for a conglomerate to grow and prosper are not exactly the same as those 
necessary for it to have sustainable success. The tools resulting from this research, and the continuing knowledgebuilding in this area will be valuable aids in building a better industry.

\section{References}

Adler, B.E. (1993). Financial and political theories of American corporate bankruptcy. Stanford Law Review, 311 346.

Adnan, A.T.M., Hossain, A., Adnan, A., \& Hossain, A. (2016). Impact of M\&A announcement on acquiring and target firm's stock price: An event analysis approach. International Journal of Finance and Accounting, 5(5), 228-232.

Akintoye, A., Beck, M., \& Hardcastle, C. (Eds.). (2008). Public-private partnerships: managing risks and opportunities. John Wiley \& Sons.

Aziz, S., Lilti, J., \& Elbadraoui, K. (2016). Tracing the M\&A footprints in bailouts and credit ratings of European banks during the 2008 financial crisis. Available at SSRN 2748576.

Battiston, S., Gatti, D.D., Gallegati, M., Greenwald, B., \& Stiglitz, J.E. (2012). Default cascades: When does risk diversification increase stability? Journal of Financial Stability, 8(3), 138-149.

Bain, J.S. (1956). Barriers to new competition. (Vol. 329). Cambridge, MA: Harvard University Press.

Berkovitch, E., Israel, R., \& Zender, J.F. (1998). The design of bankruptcy law: A case for management bias in bankruptcy reorganizations. Journal of Financial and Quantitative Analysis, 33(4), 441-464.

Black, B.S. (1988). Bidder overpayment in takeovers. Stanford Law Review, 41, 597.

Chan, A.P., Scott, D., \& Lam, E.W. (2002). Framework of success criteria for design/build projects. Journal of Management in Engineering, 18(3), 120-128.

Damgaard, J., Elkjaer, T., \& Johannesen, N. (2019). Phantom investments. Finance \& Development.

Dohrenwend, B.P. (1959). Egoism, altruism, anomie, and fatalism: A conceptual analysis of Durkheim's types. American sociological review, 466-473.

Finkelstein, S. \& Hambrick, D. (1996). Strategic leadership. St. Paul: West Educational Publishing.

Finkelstein, S., Hambrick, D., \& Cannella, A.A. (2009). Strategic leadership: Theory and research on executives, top management teams, and boards. Strategic Management, Oxford University Press, USA.

Goodpaster, K.E. (1991). Business ethics and stakeholder analysis. Business Ethics Quarterly, 53-73.

Gray, H., Besosa, R., \& Wimmer, L. (2015). Failed integrations are the seed bed for turnaround work: The pitfalls of corporate M\&A strategy. The Journal of Private Equity, 18(3), 19-20.

Hackney, W.P., \& Benson, T.G. (1981). Shareholder liability for inadequate capital. University of Pittsburgh Law Review, 43, 837.

Hongjiang, L.I.U. (2015). The innovation incentives of firms in M\&A activity - based on the empirical study of listed firm M\&A cases. Science and Technology Management Research, 2015(15), 4.

Ireland, R.D. \& Hitt, M.A. (1999). Achieving and maintaining strategic competitiveness in the 21 st century: The role of strategic leadership. Academy of Management Perspectives, 13(1), 43-57.

Jagtiani, J.A., Lemieux, C.M., \& Shin, G.H. (2000). Predicting inadequate capitalization: Early warning system for bank supervision. Chicago, IL: Federal Reserve Bank of Chicago.

Khoo, J., Durand, R.B., \& Rath, S. (2017). Leverage adjustment after mergers and acquisitions. Accounting \& Finance, 57, 185-210.

Klomp, J. (2014). Financial fragility and natural disasters: An empirical analysis. Journal of Financial Stability, 13, 180-192.

Kotter, J.P. (2008). Corporate culture and performance. Simon and Schuster.

$\mathrm{Ku}, \mathrm{S} . \mathrm{W}$. (2014). Consulting for establishing management succession plan from military lessons. Journal of Management Consulting, 14(2), 359-377.

Kucséber, L.Z. (2016). Before and after acquisition in Hungary: Focus on working capital management. Financial and Economic Review, 15(1), 70-90.

Li, X. \& Wang, S. (2016). Investigation of the Relationship between M\&A and Corporate Hedge.

Ling, F.Y.Y., Chan, S.L., Chong, E., \& Ee, L.P. (2004). Predicting performance of design-build and design-bidbuild projects. Journal of Construction Engineering and Management, 130(1), 75-83.

Longstaff, F.A. (2009). Portfolio claustrophobia: Asset pricing in markets with illiquid assets. American Economic Review, 99(4), 1119-44. 
Maupin, R.J. (1987). Financial and stock market variables as predictors of management buyouts. Strategic Management Journal, 8(4), 319-327.

McDowell, W.C., Harris, M.L., \& Geho, P.R. (2016). Longevity in small business: The effect of maturity on strategic focus and business performance. Journal of Business Research, 69(5), 1904-1908.

Moeller, S.B., Schlingemann, F.P., \& Stulz, R.M. (2004). Firm size and the gains from acquisitions. Journal of Financial Economics, 73(2), 201-228.

Olante, M.E. (2013). Overpaid acquisitions and goodwill impairment losses-Evidence from the US. Advances in Accounting, 29(2), 243-254.

Osborne, S. (2002). Public-Private Partnerships: Theory and practice in international perspective. Routledge.

Ostrom, E. (2009). A general framework for analyzing sustainability of social-ecological systems. Science, 325(5939), 419-422.

Pena-Mora, F. \& Li, M. (2001). Dynamic planning and control methodology for design/build fast-track construction projects. Journal of Construction Engineering and Management, 127(1), 1-17.

Rehman, A.U., Wang, M., \& Kabiraj, S. (2017). Working capital management in Chinese firms: An empirical investigation of determinants and adjustment towards a target level using dynamic panel data model. Afro-Asian Journal of Finance and Accounting, 7(1), 84-105.

Röpke, W. (2014). A humane economy: the social framework of the free market. Open Road Media.

Rothwell, W.J. (2010). Effective succession planning: Ensuring leadership continuity and building talent from within. Amacom.

Sainani, S. \& Chris F. (2017). How Do CFOs Matter? Evidence from M\&A.

Salvi, A., Petruzzella, F., \& Giakoumelou, A. (2018). Green M\&A deals and bidders' value creation: The role of sustainability in post-acquisition performance. International Business Research, 11(7), 96.

Spence, A.M. (1981). The learning curve and competition. The Bell Journal of Economics, 49-70.

Sturkenboom, J., Van Der Wiele, T., \& Brown, A. (2001). An action-oriented approach to quality management selfassessment in small and medium-sized enterprises. Total Quality Management, 12(2), 231-246.

Tao, Q., Sun, W., Zhu, Y., \& Zhang, T. (2017). Do firms have leverage targets? New evidence from mergers and acquisitions in China. The North American Journal of Economics and Finance, 40, 41-54.

Trueman, B. (1986). The relationship between the level of capital expenditures and firm value. Journal of Financial and Quantitative Analysis, 21(2), 115-129.

Vera, D. \& Crossan, M. (2004). Strategic leadership and organizational learning. Academy of Management Review, 29(2), 222-240.

Volberda, H.W. (1996). Toward the flexible form: How to remain vital in hypercompetitive environments. Organization Science, 7(4), 359-374.

Weinstein, I. (1984). The future of the MIO in a price-competitive, price-driven market. Topics in Health Care Financing, 11(2), 84-92.

Seal, W. (2001). Management accounting and the challenge of strategic focus. Management Accounting Research, 12(4), 487-506.

Yelle, L.E. (1979). The learning curve: Historical review and comprehensive survey. Decision Sciences, 10(2), 302328.

Zhao, K. (2017). Executive Compensation and Acquisition Decisions: Revisiting the Impact of CEO Equity Incentives on M\&A.

Zou, Q., Hu, Y., \& Huang, J.S. (2015). Definition of complex Hurst and fractional analysis for stock market fluctuation. Industrial Engineering, Management Science and Applications, Springer, Berlin, Heidelberg, 215 227. 